\title{
Ethical Analysis of Taiwanese Psychiatric Patient's Autonomy: By Jonsen's Decision Making Model and Confucianism
}

\section{MeiHsiu Lee*}

Graduate Institute of Philosophy, National Central University. Jhongli City, Taoyuan County, Taiwan

\begin{abstract}
The autonomy of psychiatric patients has been a popular issue worthy of debate. Because of the cultural background of Taiwan, families often become involved in the autonomous implementation of psychiatric patients, resulting in ethica dilemmas. Regarding medical indications, psychiatric patients can implement autonomy when their decisions do not violate the goals of medical care. The implementation of patient autonomy is respectful not only to patient preferences but also their humanity. For patients, quality of life is subjective; respecting quality of life from patient preferences conforms to the principles of beneficence, nonmaleficence and autonomy. Regarding medical decision making, treatment decisions can affect the interest of families. Taiwanese are affected by Confucianism, which emphasizes the importance of family relations and the intimacy between patients and their families. Therefore, families play an essential role in clinical decision making. This study explores the ethical autonomy of Taiwanese psychiatric patients via Jonsen's decision making model and the perspective of Confucianism to determine whether Jonsen's ethical decision making model is adaptive in Taiwanese society.
\end{abstract}

Keywords: Autonomy; Confucianism; Ethical decisions; Psychiatric patient

\section{Jonsen’s Decision Making Model}

The concept of the clinical ethical decision-making model proposed by Jonsen et al. (as shown in the Table 1) [1] originates from the four principles of Principlism. Combined with clinical practical experience and information from literature, the concept of principlism was transformed (from an abstract concept into clinical terminology and key points that should be considered) into four factors that must be considered when making clinical ethical decisions. These four factors are (1) medical indications, which are established on the principles of beneficence and non-maleficence; (2) patient preferences, which are established on the principle of respect for autonomy; (3) quality of life, which is established on the principles of beneficence, non-maleficence, and respect for autonomy; and (4) contextual features, which are established on the principles of justice and fairness. Therefore, the moral basis of the principles applied in the model for ethical decisionmaking proposed by Jonsen et al. [1] is common morality. However, despite originating from the concept of principlism, these four factors are not abstract. Instead, they are specific and can better reflect the difficulties encountered in clinical practice. The contents of the four factors provide a reference for identifying and clarifying the ethical issues medical personnel may encounter in clinical cases, thereby enabling appropriate medical decisions. Therefore, this model may enable medical personnel to resolve ethical issues. Although clinical environments are changeable and the ethical issues of each case may differ, we infer that all ethical problems involve the four identified factors. These four factors provide a systematic method for recognizing ethical issues and facilitate the analysis and resolution of these issues. Because the structure of the four factors is specific, practical, and associated with clinical practice requirements, they have received significant attention in domestic and foreign medical fields. These four factors have been applied to clinical practices to analyze ethical issues and solve ethical dilemma.

\section{Ethical Autonomy of Taiwanese Psychiatric Patients}

Psychiatric patients have been discriminated against and stigmatized, and they sometimes loss their mental capacities due to disease; therefore, some believe that psychiatric patients are unable to perform autonomously (Table 2). However, not all the psychiatric patients are disabled. We must respect those who maintain their faculties and their autonomy. The autonomy of psychiatric patients has been debated for years in clinical practice. Family intervention in treatment decision making can create ethical dilemmas, puzzling medical staff. Currently, the literature on the autonomy of psychiatric patients is inadequate. Understanding the importance and related analyses on ethical issues can assist medical staff in improving health care quality. To resolve these ethical dilemmas, this study employed the four factors of Jonsen's ethical decision making model. This study also uses the decision-making model to determine whether the model is adaptable to the Taiwanese. Finally, we explain related ethical issues from the perspective of Confucianism.

\section{Case}

Miss Wong, a 29 year old unmarried woman. Diagnosis: Chronic Schizophrenia. She has been disturbed by this disease six times since the age of 21 . She exhibits the symptoms of wandering outside, an inexpressive complexion, self-talking, and giving an irrelevant answer when in dialogue with others.

Her illness improved after she took medication regularly, and she was sent home. However, she soon collapsed because she stopped taking medication. She was raped several times and D\&C (Dilatation \& Curettage) four times. Her family complained of the enormous effort

*Corresponding author: MeiHsiu Lee, MS, Graduate Institute of Philosophy National Central University, Room 43, 9F., No. 225, Shihjian Rd., Jhongli City Taoyuan, County 320, Taiwan, Tel:+886929015193; Fax: 0028863-4163667 E-mail: lee346333@yahoo.com.tw

Received August 10, 2012; Accepted October 18, 2012; Published October 27 2012

Citation: Lee M (2012) Ethical Analysis of Taiwanese Psychiatric Patient's Autonomy: By Jonsen's Decision Making Model and Confucianism. J Clinic Res Bioeth 3:139. doi:10.4172/2155-9627.1000139

Copyright: $\odot 2012$ Lee M, et al. This is an open-access article distributed unde the terms of the Creative Commons Attribution License, which permits unrestricted use, distribution, and reproduction in any medium, provided the original author and source are credited. 


\section{The Four Topics Chart}

\section{Medical Indications}

The Principles of Beneficence and Nonmaleficence

1. What is the patient's medical problem? Is the problem acute?

chronic? critical? Reversible? emergent? terminal?

2. What are the goals of treatment?

3. In what circumstances are medical treatments not indicated?

4. What are the probabilities of success of various treatment options?

5. In sum, how can this patient be benefited by medical and nursing

care, and how can harm be avoided?

Quality of Life

The Principles of Beneficence and Nonmaleficence and Respect for

Autonomy

1. What are the prospects, with or without treatment, for a return to nor-

mal life, and what physical, mental, and social deficits might the patient experience even if treatment succeeds?

2. On what grounds can anyone judge that some quality of life would be undesirable for a patient who cannot make or express such a judgment? ti

3. Are there biases that might prejudice the provider's evaluation of the patient's quality of life?

4. What ethical issues arise concerning improving or enhancing a

patient's quality of life?

5. Do quality-of-life assessments raise any questions regarding changes

in treatment plans, such as forgoing life-sustaining treatment?

6. What are plans and rationale to forgo life-sustaining treatment?

7. What is the legal and ethical status of suicide?

\section{Patient References}

The Principle of Respect for Autonomy

1. Has the patient been informed of benefits and risks, understood this information, and given consent?

2. Is the patient mentally capable and legally competent, and is there evidence of incapacity?

3. If mentally capable, what preferences about treatment is the patient stating?

4. If incapacitated, has the patient expressed prior preferences?

5. Who is the appropriate surrogate to make decisions for the incapacitated patient?

6 . Is the patient unwilling or unable to cooperate with medical treatment? If so, why? Contextual Features

The Principles of Justice and Fairness

1. Are there professional, interprofessional, or business interests that might create conflicts of interest in the clinical treatment of patients?

2. Are there parties other than clinicians and patients, such as family members, who have an interest in clinical decisions?

3. What are the limits imposed on patient confidentiality by the legitimate interests of third parties?

4. Are there financial factors that create conflicts of interest in clinical decisions?

5. Are there problems of allocation of scarce health resources that might affect clinical decisions? 6. Are there religious issues that might influence clinical decisions?

7. What are the legal issues that might affect clinical decisions?

8. Are there considerations of clinical research and education that might affect clinical decisions? 9. Are there issues of public health and safety that affect clinical decisions?

10. Are there conflicts of interest within institutions and organizations (e.g., hospitals) that may affect clinical decisions and patient welfare?

Table 1:

\section{Medical Indications}

Medical problem:

(1) Patient has some psychotic symptoms.

(2) Non-Adherence to Medication

(3) Treatment goals: the patient can return to his or her community.

Quality of Life

Return to normal quality of life.

Patient Preferences

After recovery, the patient expressed the desire to bear children and to have a family.

Contextual Features

Family complained of the enormous effort involved in taking care of her, and suggested a Hysterectomy (uterus excision).

The importance of patient autonomy

Table 2: Psychiatric patient autonomy and Jonsen's decision making model.

involved in taking care of her, and suggested Hysterectomy (uterus excision).

But when Miss Wong returned to normal, she expressed the desire to have children and a family.

Autonomy refers to the ability of a rational individual to make decisions on his/her own without being influenced by external factors, such as manipulations and threats, resulting in spontaneous actions after rational thinking. Beauchamp and Childress (2009) believe that personal autonomy encompasses, at minimum, self-rule that is free from both the controlling interference of others and from certain limitations, such as an inadequate understanding that prevents meaningful choice [2].

According to Kant (1785) in "The Formula of Autonomy": The Idea of the will of every rational being as a will which makes universal law [3]. The meaning is that: the free will of every rational being is a universal law. Humans are rational and have free will; hence, we can establish and follow rules. With rationality, humans possess dignity and values. After psychiatric patients receive adaptive medical care, the symptoms of disease can be mitigated. When psychiatric patients have the capacity to express their own rational opinions, we must respect and adopt them. This is done out of respect to the patient's humanity. Respect for the patient's humanity, values, and dignity can have a positive impact on treatment results.

The assessment of the behavioral capacity of psychiatric patients and issues related to surrogate.
Not all psychiatric patients are incapable. Hence, we must respect the decisions made by capable patients. Regarding the assessment of capacity, Beauchamp and Childress (2009) introduced their "Rival Standards of Incompetence." The following schema expresses the range of inability currently required by competing standards of incompetence. These standards range progressively from one, requiring the least ability, to the other end of the spectrum [4].

(1) Inability to express or communicate a preference or choice.

(2) Inability to understand one's situation and its consequences.

(3) Inability to understand relevant information.

(4) Inability to give a reason.

(5) Inability to give a rational reason (though some supporting reasons may be given).

(6) Inability to provide risk/benefit-related reasons (though some rational supporting reasons may be given).

(7) Inability to reach a reasonable decision (as judged, for example, by a reasonable person standard).

In clinical practice, the MacArthur Competence Assessment Tool (MacCAT-T) can be used for assessing patient decision-making ability. When a patient is incapable, the patient's representative must make medical decisions based on the interest of the patient.

The medical decision made by the surrogate must be based on the principles of nonmaleficence and beneficence. According to 
the research of Beauchamp and Childress (2009), the concept of nonmaleficence is explained as follows [5]:

1. One ought not to inflict evil or harm.

2. One ought to prevent evil or harm.

3. One ought to remove evil or harm.

4. One ought to do or promote good.

When surrogate make medical decisions, they must consider the best interest and the risk-benefit analysis of the disease of patients. However, the decisions made by surrogate have limitations. When the rights and decision-making of patients are not consistent with the decisions made by families, and the right of patients is harmed, patients can ask for legal recourse, preserving the interests of patients.

Buchanan and Brock (1990) stated the intervention principle: the family should be disqualified if the patient is abused or neglected, or if there is a serious conflict of interest likely to bias their decisions against the rights and interests of the patient. The medical chief of staff may rebut the authority of the family [6]

\section{Ethical Issue Analysis using Jonsen's Ethical Decision Making Model}

\section{Medical indications}

(1) What is the patient's medical problem? (2) What are the goals of treatment? (3) In sum, how can this patient benefit from medical and nursing care, and how can harm be avoided?

The primary medical problem of the case subject is the nonadherence to medication, resulting in inconclusive treatment results. Therefore, medical staff should teach the research subject and families the importance of adherence to medication, the goal of treatment (return to their community), and the risk and side effects of nonadherence. Based on their professional medical background, physicians must give appropriate suggestions to patients. Therefore, patients (or families) can select treatments according to patient preferences and quality of life (for example, oral prescriptions for mental disorders can be replaced with long-acting anti-psychotics if patients cannot adhere to the medications). Physicians should consider the interest of patients to minimize harm.

\section{Patient preferences}

(1) Has the patient been informed of the benefits and risks, understood this information, and given consent? (2) Is the patient mentally capable and legally competent, and is there evidence of incapacity? (3) If mentally capable, what treatment preferences is the patient stating? (4) If incapacitated, has the patient previously expressed preferences? (5) Who is the appropriate surrogate to make decisions for the incapacitated patient?

When the families decided to conduct a uterus excision on the research subject, the subject was incapacitated due to the occurrence of mental disorder, and did not understand the risks and results of the operation. Moreover, when the subject's condition improved (nearly capable of communicating with others), she expressed a desire to get married and have a family. Therefore, physicians should explain the effects and risks of the operation, and respect the decision made by the subject while the subject is capable. The subject should be treated with dignity, as with all other humans. According to "The Formula of Ends" proposed by Kant (1785), "Act in such a way that you always treat humanity, whether in your own person or in the person of any other, never simply as a means, but as a means, but always at the same time as an end [7]." Most philosophers who find that" Kant's views attractive find them so because of the Humanity formulation of the CI (Categorical Imperative). This formulation states that we should never act in such a way that we treat Humanity, whether in ourselves or in others, as a means only but always as an end in itself. This is often seen as introducing the idea of "respect" for persons, for whatever it is that is essential to our Humanity [8].

According to the definition of "The Formula of Autonomy" proposed by Kant, each rational being can establish and follow rules through his or her own will, forming the realm of ends; namely, a person can be the one to both establish and follow rules at the same time. Regarding the definition of "the realm of ends," Kant stated that in the kingdom of ends: everything has either a price or a dignity. If it has a price, something else can be put in its place as an equivalent; if it is exalted above all price and so admits of no equivalent, then it has a dignity [9].

Kant believed that humans have values and dignity which cannot be exchanged for other things. The dignity of humans is not a tool or means, but it should be regarded as an end. According to the definition of "The Formula of Autonomy", the autonomy and right of actors deserve the respect of others. Physicians should explain the benefits and risk of treatments to patients through communication. Therefore, physicians can better understand the willingness of patients and adjust medical goals accordingly.

During the period when the patient exhibited optimal mental status and functions, her cognitive functions, reality testing, judgment abilities, and affect nearly reached the reference level. She could calculate the accounts, purchase goods, and interact with customers independently. However, regarding issues such as marriage and raising children for the patient, medical staff were required to counsel the patient and her family. The discussion content included the following: the obligations and responsibilities of marriage and raising children, the risks the drugs may pose to a fetus, the possible consequences of discontinuing or changing medicine because of pregnancy, the importance of regular medication consumption for improving her condition and overall satisfaction with life, the probability of schizophrenia inheritance, and the impact that recurrent conditions have on children and marriage. Caring for children and maintaining a marriage are stresses that can induce recurrent conditions. After discussing these issues with the patient, we understood the views and perceptions of the patient and her family. During the discussion, medical staff provided professional suggestions from an unbiased and uncritical role to avoid damaging the patient's self-esteem.

\section{Quality of life}

(1) What are the prospects, with or without treatment, for the patient to a normal life; and what are the physical, mental, and social deficits the patient might experience even if treatment succeeds? (2) On what grounds can one judge that some quality of life would be undesirable for a patient who cannot make or express such a judgment? (3) Are there biases that might prejudice the provider's evaluation of the patient's quality of life?

Quality of life is subjective, and observation by others can produce bias. Clinicians must explain to patients the possible effects on life quality that different treatments or the lack of treatment will have. Physicians also have to understand the expectations of patients on 
life, whether patients decide to take treatment or not, and the patients' opinions on the physical, mental, and social influence treatments have on the patients. Hence, improving the patient's quality of life is based on the ethical perspectives of beneficence, nonmaleficence, and respect for autonomy. Other people subjectively assess patient life quality when patients lose the capacity to express their opinions and volition. People have their own beliefs and values. Therefore, the opinions of observers can be inconsistent with those of patients, which can produce bias. To avoid excessive bias, observers should be as neutral as possible, and assess patient life quality based on the desires and best interests of patients, such as through the dialogue of patients with their families and friends, and the patient's diaries.

During the period when the patient exhibited optimal mental status and functions, the patient's Global Assessment of Functioning $(\mathrm{GAF})=81-90$, according to Axis V of the Diagnostic and Statistical Manual of Mental Disorders, Fourth Edition (DSM-IV): The patient exhibited absent or minimal symptoms (e.g., the patient exhibited slight anxiety before purchasing or importing goods when raising funds and urging manufacturers as required), good functioning in all areas, interested and involved in a wide range of activities, socially effective, and generally satisfied with life. In the assessment of the Axis IV-Psychosocial and Environmental Problems of DSM-IV, the primary factor influencing the relapse of recurrent conditions in patients is missed medication doses. The reason for the patient's previous hospitalization was that her family was sometimes too busy to remind the patient to take her medication. Additionally, the patient's family believed that she had recovered because she could work normally in the store and, thus, could discontinue her medication. Furthermore, when taking her medication, the patient was occasionally asked "What medicine are you taking?" "Why are you taking medicine?" Such questions caused discomfort in the patient because she was afraid of being considered a psychopath or crazy. Furthermore, the patient believed that if she could manage working and interpersonal relationships without problems, her condition was cured; thus, she autonomously discontinued her medication.

\section{Contextual features}

Are there parties other than clinicians and patients, such as family members, who have an interest in clinical decisions?

Humans are collective beings who interact with others, forming social networks. These social networks serve the functions of support and aid. Therefore, close family members can intervene in the medical decisions. However, most families can make decisions based on the best interests of patients (which are generally correct because families know the patient's preferences), and participate in the process of medical decision making along with physicians. Jonsen (2006) suggests that patients are located in a social context of other persons with whom they have various sorts of relationships and interactions. At times, the family's interests may conflict with those of the patient: financial concerns or interfamilial disputes may spill into clinical care. The cooperation of relatives should be sought and encouraged [10].

However, the participation of families in the process of medical decision making can also lead to negative effects. Sometimes, the decisions made by family members violate medication indications. Jonsen (2006) says that in these situations, "when family pose problems about the care of the patient, it is necessary to seek and understand the reasons for their behavior and to attempt conciliation, if possible. On rare occasions, resorting to legal steps may be necessary to protect the patient. The role of families often is defined quite differently in other culture, and ethical problems will sometimes occur [10]."

In this case study, the family is frustrated with taking care of the patient, and wants the patient to receive uterine excision to prevent the patient from becoming pregnant. However, the decision made by the family obviously violates the rights of the patient. Based on the responsibilities and obligations of medical staff, when the decision of a family is inconsistent with the professional suggestions of medical staff and violates the rights of patients, medical staff must prevent the families from acting, and even appeal to legal authorities if necessary.

Clinical and literature studies have both shown that the families of psychiatric patients play the role of caregivers, bearing significant stress. When the patient returned home, her worry and anxiety increased. The patient continuously presented problems, and her family was required to cope with the consequences. Thus, a "burn out" was unavoidable. To address this situation, medical staff must interview and psychologically support (understand the perceptions of her family through empathy) to establish the patient's family's trust in the healthcare system. Communicating the importance of taking medication on time may prevent the patient's recurrent symptoms. Additionally, medical staff must inform the family that to prevent the same problem from occurring repeatedly, clinicians will establish certain strategies to manage the patient's problems and use this to ease the family's emotions. A number of hospitals even host family support groups to enable people to share their care giving experiences. During the interactive process with group members, positive attitudes were achieved to manage the stress of caring for patients.

\section{Related Ethical Issue Analysis via the Perspective of Confucianism}

In clinical practice in Taiwan, we find that even if patients are capable (not all patients were suffering from psychological disorders) of making medical decisions, families make decisions for them, particularly when facing ethical dilemmas. This is because of the traditional background of Confucianism, which emphasizes the relationship of family and familial ethics. In addition, because patients are sick and mentally incapable, the decision-making and thinking capacities of the patients are weakened. Therefore, the families and physicians of the patients discuss and make the most adaptive medical decisions for the patients. Lee (2007) postulates: In many Asian countries that have been influenced by Confucianism, the family continues to play a central role in medical decision-making [11].

There are five human relationships in Confucianism, including the relations between ruler and subjects, father and son, husband and wife, elder and younger brother, and between friends. (the original from Mengzi-T'eng Wen Kung). Yang says "The five human relationships refer to the affectionate relationships between fathers and sons, the righteous relationships between sovereigns and ministers, the attention to separate the functions of husbands and wives, a proper order between old and young, and the fidelity relationships between friends [12].” The five human relationships begin from familial relationships and are gradually developed in political societies, forming a harmonious ethical relationship between family and society. In Taiwan, most families participate in the process of medical decision making. Based on the best interests of the patients, families discuss the benefits and risks of related treatments with physicians, and make the most appropriate medical decision.

Chen and Fan [13] believe that the Chinese family-based and 
harmony-oriented model of medical decision making is like as well as how it differs from the modern Western individual-based and autonomy-oriented model in health care practices. The roots of the Chinese model are in the Confucian account of the family and the Confucian view of harmony [13]. Fan [14] said that the focuses on the issue of surrogate decision making to illustrate the Confucian familygrounded communitarian bioethics. In Chinese bioethics, functions as a whole to provide consent for significant medical and surgical interventions when a patient has lost decision-making capacity. The Chinese model, as well as the Confucian communitarian life of families, engages a family autonomy that is supported by a Confucian understanding of moral autonomy, rather than individual autonomy. Finally, the issue of possible conflicts between patient and family interests in relation to a patient's past wishes in the Chinese model is addressed in light of the role of the physician [14].

Therefore, according to Confucian perspective it do not depends on the family's wishes over the patient's preference. If there is difference medical opinion between patient and family, then the medical staff may help them to make consistent decision. If the opinion still do not coordinate then it depends on the patient's wish, but it should not violate the best medical interest of patient.

\section{The Application of Jonsen's Ethical Decision Making Model in Taiwan and Related Problems-A Family without Confucianism}

Individualism is highly emphasized in western society. If a patient is capable, the patient's family must respect their decisions. However, Chinese society is highly influenced by Confucianism; the intimate relationship between the individual and the family is inseparable, resulting in the participation of families, patients, and physicians in the medical decision making process. However, sometimes, whether patients are capable or not, they are excluded from the decisionmaking process. Though Jonsen's decision making model considers the necessity of family intervention in medical decision making and its potential for error, the model neglects the fact that the meaning of family among Chinese is derived from Confucianism, and the importance of family intervention in medical decision making. In Chinese families, the intervention of family in medical decision making is a common phenomenon, which is also a unique to Chinese culture.

$\mathrm{Li}$ and Wen [15] write that the Confucian family-determination model has been applied in Chinese society for thousands of years. Based on summarizing the reasons supporting the model, this essay indicates that it is an integral part of the model that in emergency or special cases, the physician must take medical action to save the patient, without the need to secure the consent of a family member. Chinese physicians must cultivate the Confucian virtue of benevolence in their practice of taking care of patients in a virtuous way, along with the patients' families [15].

Lee [16] reports the following: The "ethical relational theory of autonomy" integrates the Confucian concept of a person, which asserts that our relations with others, and in particular our family, are part of our personal identity. This theory of autonomy also has an ethical component: it takes into account the Confucian insight into the nature of moral experience, which as Lee shows, is quite similar to Kantian notion of autonomy. Lee argues that an autonomous action is an action that (1) is circumscribed by the "moral mind" or what would Kant terms "practical reason" and (2) this moral mind must be oriented to the welfare of others because their wellbeing is closely linked to our own welling and identity. The second feature of this theory takes into account the family, because our moral practice begins with the wellbeing of family members as they are so integral to our own identity and wellbeing. Lee concludes by arguing such a theory requires that medical decision making be a collective affair that involves both patients and their families [16].

The author discusses family decision-making only in certain contexts, which indicates the inadequacy of the literature on family intervention. A Taiwanese family often involves four topics chart. This presents the differences between Western Individualism and Eastern Familialism in clinical ethical decision-making. For vulnerable parties, family decision-making sometimes is good, and sometimes bad (it doesn't always consider the best interests of the patient). Therefore, medical care personnel must protect the patient from harm. Application of the theory of Jonsen's decision-making model is too widespread. It does not provide explanations about representative decision-making. The cross-cultural discussion is insufficient. For example: the author does not consider Confucian, Family-Centered Decision. But they are very important for Asian's patient/family to make ethical decision.

\section{Conclusion}

Ambrosini and Crocker (2009) report that psychiatric advance directives (PADs) are grounded in the ethics of autonomy. PADs are legal documents that allow individuals with mental illnesses to record their preferences for treatment should they become incompetent in the future. Autonomy is the value that empowers individuals to work toward their recovery [17].

From the perspective of Kant's theory, humans are rational beings who can establish and follow moral principles, possess autonomy, and treat themselves and others as ends instead of means; therefore, humans have dignity and values. Kant (1785) stated: Man, and in general every rational being, exists as an end in himself, not merely as a means for arbitrary use by this or that will [18].

Regarding the case study in this research, the patient's decision was not aligned with that of the family; thus, medical staffs have the right to prevent the family from making a medical decision. In Chinese society, individuals and families are regarded as a whole, and families make medical decisions for patients; though in some cases, patients can be capable. However, medical staff should prevent families from making decisions when such decisions violate the best interests of patient.

Even if the patient had not expressed her wish, the hysterectomy (uterus excision) could not have been performed. The philosophy of Confucianism would not support performing the operation on the patient. In this case, there were no medical indications that could justify this operation. When the patient was capable, she expressed her preference; therefore, her opinions must be respected. Respect for patient autonomy is a manifestation of respect for humanity. Medical staff can prevent the decisions made by representatives when those decisions violate the preferences of patients. Medical staff can suggest that representatives discuss these decisions with patients when patients are capable of doing so. Therefore, according to the best interests of the patient, the hysterectomy could not be performed. The discussion of whether to perform a hysterectomy should be conducted by medical staff. Medical staff can suggest the families use an intrauterine contraceptive or contraceptive patch under the premise of protecting the patient.

Although the reason the patient discontinued her medication was that she "forgot to take the medicine," questions and problems were 
developed based on (1) perceived health leading to the discontinuation of medication consumption; (2) the fear of being considered a psychopath or crazy because of the consumption of medicine; and (3) the family's failure to remind the patient to consume her medication on time. Regarding this problem, we suggest that medical staff conduct the following procedures: (1) Provide health education regarding the importance of consuming medication on time to prevent a relapse for the patient and her family. (2) inform the patient and her family that her oral drugs could be replaced using long-acting antipsychotic drugs. If the drug efficacy is not ideal, medical staff must consider replacing drugs and adjusting the dosage and administration methods. After her condition improved, the patient was transferred to the Day Care Ward to facilitate observation of the efficacy of long-acting antipsychotic drugs and the patient's degree of recovery. (3) When the patient achieved remission of her condition, she was reclassified as a Home Visit case. Subsequently, medical staff let the patient return to the community for deinstitutionalization. (4) Medical staff were responsible for conducting regular home visits. The OPD nurses staff could follow up on her condition with phone interview or transfer the patient to a psychiatry case manager. These professionals can continuously monitor the patient's condition and conduct GAF Scale and Psychosocial and Environmental Problems assessments. If a problem is identified, adequate intervention can be provided to resolve the issue. These measures enable the patient's family to understand that other ways for ensuring the patient's drug compliance and return to normal life exist. The family also has a responsibility and obligation to urge the patient to take her medication. Adopting the extreme method of a hysterectomy is not required to resolve related problems. This treatment exemplifies a spiritual or performance of ethical meaning that balances beneficence, nonmaleficence, and justice to provide a treatment the patient deserves.

\section{References}

1. Jonsen AR, Siegler M, Winslade WJ (2010) Clinical Ethics: A Practical Approach to Ethical Decisions in Clinical Medicine. New York: McGraw-Hi I I: 8.

2. Beauchamp TL, Childress JF (2009) Principles of Biomedical ethics. New York: Oxford University press: 99

3. Kant I (writings), Paton HJ (translate) (1964) Groundwork of the metaphysic of morals .(German:Grundlegungzur Metaphysik der Sitten, 1785). New York: Harper \& Row: 98.

4. Beauchamp TL, Childress JF (2009) Principles of Biomedical ethics. New York Oxford University press: 114-115.

5. Beauchamp TL, Childress JF (2009) Principles of Biomedical ethics. New York: Oxford University press: 150

6. Buchanan AE, Brock DW (1990) Deciding for others: the ethics of surrogate decision making. New York: Cambridge Universi ty Press: 142.

7. Kant I (writings), Paton HJ (translate) (1964) Groundwork of the metaphysic of morals. (German:GrundlegungzurMetaphysik der Sitten, 1785). New York: Harper \& Row: 96.

8. Kant's Moral Philosophy: First published Mon Feb 23, 2004; substantive revision Sun Apr 6, 2008.

9. Kant I (writings), Paton HJ (translate) (1964) Groundwork of the metaphysic of morals. (German:GrundlegungzurMetaphysik der Sitten, 1785). New York: Harper \& Row: 102.

10. Jonsen AR, Siegler M, Winslade WJ (2010) Clinical Ethics: A Practical Approach to Ethical Decisions in Clinical Medicine. New York: McGraw-Hi I I: 167.

11. Lee SC (2007) The Family, Medical Decision-Making, and Biotechnology: Critical Reflections on Asian Moral Perspectives. Dordrecht: Springer, Kluwer Academic Publishers: 4.

12. Yang BJ (1962) Mengzi's Translation and Interpretations. Shanghai: Chung Hwa Book: 128.

13. Chen X, Fan R (2010) The family and harmonious medical decision making: cherishing an appropriate Confucian moral balance. J Med Philos 35: 573-586.

14. Fan $R$ (2011) The Confucian bioethics of surrogate decision making: its communitarian roots. Theor Med Bioeth 32: 301-313.

15. Li EC, Wen CF (2010) Should the Confucian family-determination model be rejected? A case study. J Med Philos 35: 587-599.

16. Lee SC (2007) The Family, Medical Decision-Making, and Biotechnology: Critical Reflections on Asian Moral Perspectives. Dordrecht: Springer, Kluwer Academic Publishers: 5-6.

17. Ambrosini DL, Crocker AG (2009) Psychiatric advance directives and the role of autonomy. Sante ment Que 34: 51-74.

18. Kant I (writings), Paton HJ (translate) (1964) Groundwork of the metaphysic of morals. (German:GrundlegungzurMetaphysik der Sitten, 1785). New York: Harper \& Row: 95 